\title{
Patrimonio cultural y patrimonio antropológico
}

\author{
SALVADOR RODRÍGUEZ BECERRA \\ Dpto. de Antropología Social \\ Universidad de Sevilla
}

En el concepto común y jurídico del patrimonio se incluyen todos los recursos que se heredan, bienes muebles e inmuebles y capitales, y de los que se vive o que ayudan a vivir. Estos bienes se incrementan, disminuyen, desaparecen o transforman y se trasmiten a los descendientes. Incrementarlos ha sido en nuestra sociedad un ideal y un valor positivo, malgastarlos o, simplemente, venderlos se ha considerado un baldón o al menos un valor negativo. Covarrubias en su conocido diccionario, Tesoro de la Lengua castellana o española (1611), define el patrimonio como: "Lo que el hijo hereda del padre». Actualmente el término se ha hecho más comprensivo e incluye el conjunto de bienes, valores y créditos que posee una persona o institución (Gran Enciclopedia Catalana).

La realidad histórica señala que una importante característica del patrimonio ha sido la movilidad que, desde el final del Antiguo Régimen, se generalizó a todos los estamentos sociales, una vez abolidos los derechos de mayorazgo que limitaban la libre enajenación de los bienes patrimoniales para garantizar el mantenimiento de los linajes. Las clases dirigentes de la sociedad española durante esta etapa histórica creían haber llegado al cénit de su poder; su permanencia se garantizaba vinculando los bienes adquiridos con los linajes, con la prohibición legal de exonerarlos; en el orden espiritual, la idea de eternidad que implicaba el paso de los individuos de este mundo al otro se sustentaba en la incorporación al grupo familiar de indulgencias, misas y capellanías. El patrimonio, como puede apreciarse, cumplía fundamentalmente la función de garantizar la supervivencia de los grupos sociales y conectaba unas generaciones a otras.

Los aspectos inmateriales de la cultura no han tenido una regulación jurídica tan precisa como los bienes materiales, dada la dificultad de legislar sobre ellos por tratarse de aspectos inconmensurables, aunque también han sido considerados parte del patrimonio. Esta concepción incluye creencias, valores éticos y comportamentales que una sociedad, una clase o grupo social considera propios, que lo caracterizan y distinguen y que, 
por tanto, también deben ser trasmitidos a los descendientes. El honor, decía Calderón en el Alcalde de Zalamea, es patrimonio del alma, pero también la buena fama, la caridad o el buen gusto se consideran hereditarios y han constituido tradicionalmente parte del patrimonio.

En las anteriores definiciones domina la idea de que el patrimonio es algo para transmitir a los descendientes y modificable por las generaciones siguientes, aunque hayan existido tendencias en los ascendientes a inmovilizarlo y un anhelo de incrementarlo en los descendientes. La ley del Patrimonio Histórico de Andalucía se hace eco de estas ideas básicas cuando en su preámbulo expone: "En definitiva [...] un Patrimonio que hemos recibido y tenemos la responsabilidad de transmitirles acrecentadon.

\section{El PATRIMONIO CULTURAL: CONCEPTO Y CONTENIDOS}

Hasta ahora sólo nos hemos referido al patrimonio como algo perteneciente a un grupo familiar o de parentesco y por tanto correspondiente a la esfera de lo privado; sin embargo, está claro que el concepto de patrimonio tiene hoy una dimensión social y pública que amplios sectores de la sociedad consideran que les afecta como miembros de una comunidad política, ya sea esta entidad mayor o menor, municipio, comunidad autónoma, estado, superestado u organización internacional. Esta concepción es una novedad que hay que enmarcar en los procesos de identificación social y en la toma de conciencia de que vivimos en una "aldea global.

Las adjetivaciones del patrimonio cultural son tantas y tan confusas actualmente que me ha parecido conveniente establecer unos cuadros clasificatorios para intentar aclarar y poner un poco de orden en esta algarabía mental y terminológica, porque esta última cuestión tiene a veces más importancia de lo que pudiera parecer. Así, vemos que diversas leyes sobre el patrimonio han sido tituladas del patrimonio histórico, y ello desde nuestro punto de vista es una manifestación del peso que en toda intervención legal tiene el factor tiempo, que se convierte en un valor añadido a todo objeto, ritual o conocimiento, y aunque no es desdeñable, considero excesivo su peso en la legislación y en la política cultural. La identificación con la historia como ciencia social es también un peligro a tener en cuenta. El término Patrimonio cultural que nosotros defendemos, lo consideramos el más comprensivo de todos y hubiera sido deseable que bajo esta rúbrica se hubieran colocado todas las leyes del patrimonio.

Con este propósito incluimos en la primera tabla los distintos tipos de patrimonio que establece la ley del Patrimonio Histórico de Andalucía: 
TABLA 1

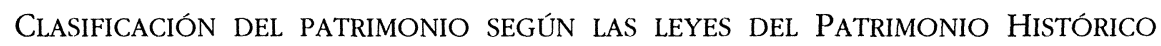
EsPaÑol (1985) Y DEL PATRIMONIO Histórico dE ANDAluCía (1991)

\begin{tabular}{|l|l|l|}
\hline Artístico & $\begin{array}{l}\text { Histórico } \\
\text { Etnográfico / Etnoló- } \\
\text { gico / Antropológico }\end{array}$ & $\begin{array}{l}\text { Paleontológico } \\
\text { Documental }\end{array}$ \\
Bibliográfico & $\begin{array}{l}\text { Científico } \\
\text { Inmueble }\end{array}$ & $\begin{array}{l}\text { Técnico } \\
\text { Inmaterial }\end{array}$ \\
\hline
\end{tabular}

En un segundo cuadro, establecemos los tipos según las realidades territoriales jurídicamente aceptadas actualmente y las futuras que reconocen o puedan reconocer el carácter patrimonial, así como la identificación de los grupos étnicos, y llevándolo hasta sus últimas consecuencias, habríamos de tener en cuenta el patrimonio de clase y hasta de grupos profesionales.

TABLA 2

CLASIFICACIÓN DEL PATRIMONIO SEGÚN EL ÁMBITO POLÍTICO-TERRITORIAL

\begin{tabular}{|l|l|l|l|l|}
\hline $\begin{array}{l}\text { Mundial o de } \\
\text { la Humanidad }\end{array}$ & [Europeo] & $\begin{array}{l}\text { Nacional } \\
\text { [Étnico] }\end{array}$ & $\begin{array}{l}\text { Autonómico } \\
\text { [Comarcal] }\end{array}$ & [Local] \\
\hline
\end{tabular}

Finalmente, proponemos nuestra propia clasificación que ordena conceptualmente los diversos sistemas clasificatorios y propone un único término, el de Patrimonio antropológico, para lo que se viene denominando patrimonio etnográfico y etnológico:

TABLA 3

ClASIFICACIÓN DEL PATRIMONIO SEGÚN EL ÁMBITO DE LA CULTURA

\begin{tabular}{|l|l|l|}
\hline \multicolumn{2}{|l|}{ Concepción totalista $u$ bolistica: Toda la cultura } \\
\hline Arqueológico / prehistórico & Histórico / documental & Antropológico \\
\hline Sectorial o de aspectos de la cultura: & $\begin{array}{l}\text { Monumental / arquitectónico } \\
\text { Artístico }\end{array}$ & $\begin{array}{l}\text { Ecológico / medioambiental } \\
\text { Literario }\end{array}$ \\
\hline Científico & Tecnológico & \\
\hline Funciones instrumentales y auxiliares: & Idiomático \\
\hline Bibliográfico & Documental &
\end{tabular}




\section{Postulados BÁsicos del Patrimonio CUlTURAL}

Antes de continuar, expondremos algunos principios sobre los que construimos nuestra concepción del patrimonio. Son afirmaciones radicales pero que conviene tener muy claras:

1) Conservar la cultura y el patrimonio en su totalidad e integridad es imposible. Partimos de esta afirmación para evitar malentendidos y actitudes demagógicas. La cultura es una construción mental elaborada como generalización a partir de hechos sociales, comportamientos y objetos que se dan en el tiempo, y por tanto cambiantes. Por ello es consustancial al patrimonio el hecho del cambio: no recibimos de las generaciones anteriores lo mismo que transmitimos a las que nos siguen. Por consiguiente no tiene razón de ser la queja lastimera y romántica, salvo como concesión a los sentimientos, ante el cambio cultural que conlleva el desuso de determinados objetos, prácticas y conocimientos. A los conservacionistas a ultranza habría que recordarles aquel personaje de Borges, "Funes el Memorioso" al que cualquier reconstrución del pasado le tomaba tanto tiempo contarla como el tiempo real transcurrido ${ }^{1}$. No obstante, a pesar de la afirmación anterior, no preconizamos un liberalismo extremo que favorezca la rápida desaparición del patrimonio tradicional, sometido a las leyes del librecambio sin cortapisa alguna. Entendemos que toda generación recibe un patrimonio $-\mathrm{y}$ este concepto no puede desprenderse del sentido de herencia, es decir, conseguido por unos y transmitido a otros - que ha contribuido a conformar su vida, su visión del mundo, su visión paisajística, su entorno vital, sobre el que ejerce algún derecho, así como sobre su transmisión a la siguiente generación, y a su vez tiene derecho a reevaluar su herencia patrimonial. Una actitud extrema, que pudiéramos llamar conservacionista nos llevaría a detener el cambio y la mejora de la calidad de vida. ¿Cómo armonizar el desarrollo con el respeto al patrimonio cultural, específicamente al patrimonio antropológico? ¿Es posible y legítima la reutilización funcional del patrimonio antropológico?

2) Desde el pasado siglo fue calando la concepción del patrimonio como bien escaso y valioso, raro y poco corriente, no utilitario. Los objetos y en general los bienes muebles perdían su valor inicial como objeto útil y ganaban un nuevo valor simbólico, económico, identitario, sentimental y hasta sagrado, como si de un fetiche se tratara. Este concepto,

1 J. BALLART, El patrimonio bistórico y arqueológico: valor y uso (Barcelona: Ariel, 1997), p. 43. 
heredado de los folcloristas, ponía el énfasis en lo propio, distintivo y autóctono, y, también, en lo rural y tradicional y en el pasado; tiene por tanto un carácter restrictivo ${ }^{2}$. Esta concepción lleva aparejada una selección de bienes - no todos los bienes son considerados dignos de conservarse-, en función de unos criterios revisables según la consideración que de lo valioso tiene cada época. Citemos algunos ejemplos: Para los románticos todo lo medieval tenía valor patrimonial, cuando para otros eran sólo ruinas; para los historiadores de las mentalidades, los exvotos, objetos deleznables o de mal gusto para muchos, se convirtieron en objetos patrimoniales dignos de conservación ${ }^{3}$, las desvencijadas y obsoletas fábricas constituyen en la actualidad monumentos patrimoniales dignos de ser estudiados y visitados por cierto turismo especializado ${ }^{4}$.

3) El concepto de patrimonio evoca sobre todo conservación. Parece fuera de toda duda que cuando hablamos de patrimonio, y ello es muy claro en el caso de las administraciones públicas, nos referimos sobre todo a conservación. Y nos surgen dos cuestiones: ¿Qué se debe o puede conservar? y ¿Para qué y para quiénes conservar? En la respuesta a la primera pregunta está implícito que se trata de conservar aquello que está en peligro de desaparición, porque lo que está vivo nadie piensa en la necesidad de protegerlo. Entre otras razones porque para muchos sólo se protege el pasado que aún perdura. Como ejemplo, citemos el patrimonio antropológico que no sólo está formado por objetos y conocimientos en declive, como el molino hidráulico o de viento, sino también por objetos y conocimientos en uso, como, verbigracia, el que posee el curandero sobre cómo curar las verrugas, o la casa del siglo xvil que sigue siendo domicilio de una familia. Conviene insistir, así mismo, en que el patrimonio antropológico, a diferencia de otras formas sectoriales, incluye objetos y conocimientos de carácter cotidiano y común y no sólo los excepcionales, obsoletos, exóticos o únicos. Hay que evitar caer en la "Sacralización" de la pieza única, que distorsiona la realidad socioeconómica en la que surgió. Volveremos sobre ello.

4) El tratamiento del patrimonio antropológico incluye las siguientes secuencias interconectadas:

a) La investigación es el fundamento de toda intervención en el patrimonio. Esta fase es muy importante -imprescindible- en el caso del

2 J. PRat y J. M. Comelles, Reunión preparatoria de los textos de la ponencia y de las comunicaciones sobre cultura popular (inédito) (Madrid: Ministerio de Cultura).

3 M. Vovelle, Ideologias y mentalidades (Barcelona: Ariel, 1985).

4 H. CAPEL, "El turismo industrial y el patrimonio histórico de la electricidad", Catalogación del Patrimonio Histórico. Cuadernos, VI (Sevilla: IAPH, 1996), pp. 170-195. 
patrimonio antropológico, pues cualquier objeto o conocimiento carecería de significado y hasta de valor sacado de su contexto cultural. La obra de arte, al decir de algunos, con los que no coincidimos, tendría valor por sí misma, independiente del contexto en el que surge. Esta secuencia supone documentar el objeto, el conocimiento o el ritual, una vez establecido su uso.

b) La conservación debe incluir la documentación, la conservación del conocimiento, y también dejar testimonios materiales, manifestaciones, procesos productivos, etc. Los museos constituyen una institución necesaria pero no exclusiva. También se conserva en los talleres, en las bibliotecas y en las videotecas; en cualquier caso el objetivo último y deseable, aunque no siempre posible, es conservar en el lugar donde se halle y por las gentes detentadoras de su propio patrimonio. Recordemos que para algunos conservar es mantener "en pie", caso de la arquitectura, y para no pocos conservar es retirar de la circulación o salvar de la destrucción guardándolo en el museo. En muchos casos conservar es fundamental y únicamente documentar. Tengamos en cuenta, no obstante, que documentar es interpretar, algo por tanto sujeto a contingencias teóricas y metodológicas. No es posible, pues, registrar fielmente como creen algunos profesionales de la etnografía.

c) La difusión debe entenderse como el dar a conocer los resultados de la investigación, como experiencia de una comunidad en el transcurso del tiempo y en unas circunstancias medioambientales concretas. La singularidad de un hecho puede ser un valor añadido pero en todo caso no puede constituirse en la única razón de su tratamiento. La difusión debe hacerse por todos los medios, incluidos los audiovisuales y desde luego debe contemplar la exhibición en museos y muestras e incorporarse a la enseñanza.

d) La restitución o devolución a los protagonistas de los resultados, con lo que ello conlleva de profundización en el conocimiento de lo propio; esto es especialmente útil en una sociedad democrática, en la que los portadores de la cultura se convierten en actores y en su caso en los agentes de conservación más eficaces. Los sujetos de la cultura dejan así de ser meros portadores, informantes y sujetos pasivos para convertirse en protagonistas de su presente y de su futuro. La beneficiaria de la restitución es la sociedad en su conjunto; a los técnicos corresponde proporcionar los mecanismos adecuados para ello. 


\section{LAS CONCEPCIONES DEL PATRIMONIO ANTROPOLÓGICO}

El concepto de Patrimonio antropológico viene definido en la Ley del Patrimonio Histórico Español que utiliza el término etnográfico, como "los bienes muebles e inmuebles y los conocimientos y actividades que son o han sido expresión relevante de la cultura tradional del pueblo español en sus aspectos materiales, sociales o espirituales" (Art. 46); posteriormente especifica que forman también parte de este tipo de patrimonio "aquellos objetos que constituyen la manifestación o el producto de actividades laborales, estéticas y lúdicas propias de cualquier grupo humano, arraigadas y transmitidas consuetudinariamente..." y también los "conocimientos o actividades que procedan de modelos o técnicas tradicionales utilizados por una determinada comunidad... Edificaciones e instalaciones cuyo modelo constitutivo sea expresión de conocimientos adquiridos, arraigados y transmitidos consuetudinariamente y cuya factura se acomode, en su conjunto o parcialmente, a una clase, tipo o forma arquitectónica utilizados tradicionalmente..." (Art. 47).

No existe un acuerdo unánime en la concepción del patrimonio antropológico, las diversas posiciones abarcan desde posturas restrictivas y parciales en las que ciertos valores predominan o excluyen a otros, así, ciertas formas estéticas, claramente imperantes hasta muy recientemente, están dando paso a una mayor apertura que incluye como valores patrimoniales saberes, ideas y conceptos. Pero las diferencias van más allá y surgen en lo que se conoce como patrimonio etnográfico, etnológico y para nosotros antropológico, recogido ya en las leyes patrimoniales elaboradas en los últimos años. Es legítimo y necesario preguntarnos, como lo hace el documento promovido por el Ministerio de Cultura español a instancias de la Unesco, elaborado por un numeroso grupo de antropólogos, por la naturaleza y los contenidos del patrimonio cultural. También hay que tener en cuenta que el campo del patrimonio no es una tierra de nadie sino que ya está parcialmente ocupada y con fuertes posiciones por la arqueología, la historia del arte, la arquitectura, la filología, y, más recientemente, la ecología, por citar algunos ejemplos. Y aunque es conveniente y es nuestra tarea como científicos sociales - a los antropólogos nos obliga especialmente, dada nuestra concepción totalista de la cultura- preguntarnos una y otra vez por la razón misma del concepto del patrimonio y sus contenidos, a la vez es conveniente y necesario que demos a la sociedad y a sus dirigentes unas pautas plausibles y no quedarnos simplemente en la especulación y en consecuencia en la queja permanente de que no se escuchan nuestras propuestas, porque como 
expertos en la cultura, entendida como vida cotidiana, que explícitamente excluye singularidades, exotismos y excepcionalidades, tenemos algo que decir. Nuestra propuesta, como expondremos al final del epígrafe, no es sólo gremialista, que también lo es, como la de las demás disciplinas consideradas con carta de naturaleza en el patrimonio, sino que creemos que cubre un amplio campo - el patrimonio antropológico- considerado actualmente por nuestra sociedad como bien patrimonial.

Entendemos el patrimonio antropológico como las creaciones culturales vivas y consolidadas, aceptando los campos específicos de otras formas de patrimonio, pero sin olvidar la interrelación que entre todos ellos existe. La denominación Patrimonio etnológico, de clara influencia francesa, supone una salida vergonzante que usan aquellos que no se atreven a usar el término antropológico porque su referencia a la antropología, ciencia actualmente con una gran carga teórica, les parece muy por encima de nivel en el que se mueven, pero también por la razón contraria, la de aquellos antropólogos que consideran que el patrimonio carece de nivel teórico para poder equipararse a la disciplina científica y es preferible usar el término etnológico, que, en la formulación levistraussiana, ocupa un rango menor de generalización. Por último, el uso del término patrimonio etnográfico, que para muchos sigue siendo referente de objetos materiales, y en otros casos, de simple descripción, es expresión de un complejo de inferioridad que no siempre tiene fundamento. Para nosotros, todo el que estudia el comportamiento humano en cualquiera de sus manifestaciones vivas con rigor metodológico hace antropología. Seguidamente exponemos las principales posiciones en la realidad personal e institucional española:

1) Tradicionalista: El Patrimonio considerado como conjunto de elementos de la cultura tradicional y popular. Desde esta postura, constituyen el patrimonio el conjunto de bienes, elementos o testimonios materiales e inmateriales que son representativos de la cultura popular de un país o región en el período preindustrial y que no pueden ser catalogados en el patrimonio artístico o arqueológico. Ha sido el objeto de estudio de folcloristas y etnógrafos.

2) Revisionista: El Patrimonio entendido como cultura tradicional tanto en el pasado como en el presente, está formado por el conjunto de elementos o testimonios de la cultura y formas de vida populares desarrolladas en el tiempo. Amplía los límites de la concepción anterior, pero se sigue definiendo por aspectos parciales del patrimonio. Incorpora claramente lo urbano e industrial. Posición de la que participan los museos etnológicos y de artes y costumbres populares. En este contexto entendemos por tradicional, la herencia recibida más los bienes adquiridos y con- 
solidados. La tradición implica herencia común, es decir, consolidada. El patrimonio se construye en el tiempo, por tanto no debe renunciarse al pasado.

3) Alternativa: El Patrimonio interpretado como cultura en un sentido antropológico. El patrimonio no es algo "dado" sino que se construye socialmente en cada época, estaría constituido, por tanto, por aquellos elementos seleccionados a los que se les otorga un valor. Se identifica con el concepto antropológico de cultura, en otras palabras, "es la cultura, o mejor todavía, el conocimiento de la cultura, en toda su complejidad y diversidad pasada y presente" ${ }^{5}$.

4) Patrimonio como cultura viva e integral: Los individuos son sujetos del patrimonio y a la vez sujetos de la cultura, en los que se da sin distinción lo recibido de lo incorporado. "No tiene sentido desde los sujetos del patrimonio, afirmar que la cultura tradicional está en peligro por el acoso de la cultura industrializada". No cabe marcar líneas infranqueables entre las condiciones de gestación de la cultura y la forma en que se transmite. El patrimonio cultural es algo integral y no constituye la suma de los patrimonios específicos. Se evita así el riesgo de fetichización de los objetos, tan frecuente en este campo. Esta postura equipara patrimonio cultural a la cultura en su totalidad ${ }^{6}$. A este respecto nos preguntamos, ¿también debemos considerar parte del patrimonio cultural la drogadicción o el movimiento hippy? Entendemos que a estas manifestaciones les falta la consolidación para pasar a formar parte del patrimonio, porque algunas de estas expresiones culturales han tenido una vida efímera. Estas expresiones, en cuanto a su problemática, son objeto de estudio de la sociología y antropología como fenómenos y comportamientos humanos, pero no son patrimoniales y dignos de ser conservados.

Esta cultura viva constituye el patrimonio cultural, y aunque la Ley del Patrimonio Histórico dedica más atención al llamado patrimonio material u objetual incluye también entre sus objetivos proteger los conocimientos tradicionales, las creencias, los valores y los comportamientos rituales. De cualquier manera, aunque el legislador ha sido sensible a la cultura como un todo, a nadie escapa que amplias parcelas de la misma no podrán conservarse de forma vívida, sino que pasarán a los archivos, bibliotecas, fonotecas, videotecas, hemerotecas, etc., y esto será siempre cultura interpretada. La antropología cultural, mediante el método comparativo y la técnica de la observación participante en un prolongado trabajo de cam-

5 Ll. Prats y M. Iniesta (eds.), El Patrimonio etnológico. Actas del VI Congreso de Antropología, VI (Tenerife: FAAEE, ACA, 1993).

6 J. Prat y J. M. Comelles, op. cit., p. 8. 
po, puede reconstruir a través de cuadros o aproximaciones la cultura de una comunidad en un tiempo concreto. Esta posición excluye otras que niegan la posibilidad de aprehender la cultura y, por tanto, de conservarla y transmitirla por ser ésta una realidad viva, cambiante e inaprensible. Desde esta perspectiva radical los objetos conservados en museos resultarían engañosos, pues un mismo objeto usado en épocas y/o culturas distintas puede tener diversas funciones y/o significados.

5) Nuestra posición: Entendemos que el patrimonio es la recuperación del pasado, desde la perspectiva del presente, para explicar las formas vivas. Ello implica la consideración de la dimensión temporal de la cultura, es decir, formas antiguas que coexisten con formas nuevas y otras que desaparecen. Esta concepción tiene en cuenta la dimensión espacial que da sentido a nuestra cultura en la comparación con otras de otros espacios y ayuda a configurar las identidades colectivas; asimismo, contempla la aparición de nuevos grupos sociales: profesionales, generacionales y de género que también van a crear su patrimonio para que se les identifique $^{7}$. En esta línea nos parece acertada la definición de patrimonio que se propone en el texto del proyecto curricular para la enseñanza secundaria en Andalucía: "El patrimonio cultural de una sociedad lo constituye el conjunto de bienes materiales, ideacionales y simbólicos que se transmiten de una a otra generación e identifican a los individuos que la componen en relación con los de otras realidades sociales" ${ }^{8}$.

Esta concepción del patrimonio, que nosotros denominamos antropológico, presupone en las sociedades una cultura propia, genuina -aunque no exclusiva- e identificable, que parte de la unidad cultural, pero reconoce la diversidad y apuesta por las relaciones con otras culturas; tiene en cuenta la trayectoria histórica y el marco geográfico donde se desarrolla; es una eficaz ayuda en el proceso de socialización, por cuanto valora la cultura propia y desarrolla el respeto a otras, combatiendo el etnocentrismo; es una concepción dinámica que excluye la visión arqueologizante; y finalmente, entiende el patrimonio como unidad integrada, no mera recopilación de datos, objetos o anécdotas. En síntesis, nuestro concepto antropológico de patrimonio implica: conjuntos integrados; cambios en los contenidos, lo que supone incremento, disminución y transformación; consolidación, que excluye lo coyuntural; resemantización o nueva valoración, diferente de la que tenía en origen, y selección entre los numerosos rasgos culturales potenciales de convertirse en patrimonio. Todo ello en un permanente proceso de transmisión, difusión y apropiación por parte de los actores sociales.

\footnotetext{
7 J. L. García, Sobre el Patrimonio Cultural (inédito) (1992).

8 BOJA, 25 sept., 1993.
} 


\section{PATRIMONIO ANTROPOLÓGICO Y ANTROPOLOGÍA}

"El patrimonio etnológico está constituido por todos aquellos objetos, elementos, prácticas, costumbres y tradiciones que son características e identificadoras de la cultra de una sociedad, fruto de sus peculiares relaciones con el medio y experiencia histórica" ${ }^{9}$. ¿No es esto una definición de cultura desde la antropología? Y sin embargo, nosotros entendemos que patrimonio cultural y antropología son dos cosas distintas, aunque muy relacionadas no siempre coincidentes. La antropología puede ilustrar la concepción del patrimonio con presupuestos como la escasa relevancia de los datos sueltos, evitar el falso problema de las urgencias - el grito, jesto se acaba!, tan extendido entre aficionados y románticos, carece de sentido en este contexto-, desacralizar los objetos patrimoniales, también los artísticos, y poner de manifiesto la centralidad de los problemas en las culturas.

Llegados a este punto cabe preguntarnos: ¿qué debe primar, la lógica científica o las necesidades sociales? La primacía la tiene la sociedad, aunque se debe poder compaginar ambas partes. Excavar una ciudad de la época romana, pongamos por caso, tiene mayor interés social que científico, por cuanto las ciudades romanas son bastante bien conocidas por los arqueólogos, pero constituyen bienes de incalculable valor históricopatrimonial. El patrimonio es una construcción social y debe hacerse desde el presente y sus necesidades, según los siguientes criterios: representar la diversidad, articular y explicar la desigualdad, afianzar la identidad, contribuir al desarrollo socioeconómico y no olvidar que el patrimonio no puede incluir todo lo que las culturas han creado. En síntesis, nuestra propuesta se articula en los siguientes apartados:

$1 .^{\circ}$ Utilizar el concepto de patrimonio cultural para el conjunto de bienes susceptibles de actuación por ser representativos de unas formas de vida en un período determinado.

2..$^{\circ}$ Incluir en el término patrimonio antropológico objetos, saberes y formas de vida susceptibles de intervención porque son representativos de una sociedad viva. Reservar los términos de antropología sociocultural para la ciencia o área de conocimiento, y los conceptos de cultura y sociedad como básicos de esta disciplina.

$\left.3 .^{\circ}\right)$ Negar el carácter restringido, marginal y en trance de desaparición atribuido actualmente a los contenidos del término patrimonio

' J. EsCAlERA REYES, "El patrimonio etnológico andaluz: Concepto, situación y perspectivas", II Jornadas de Asesoramiento a municipios (inédito) (Córdoba: Diputación de Córdoba, 1985). 
antropológico y equipararlo en contenidos a los del patrimonio arqueológico e histórico, pero referido a las sociedades vivas.

4..$^{\circ}$ Utilizar exclusivamente el término patrimonio antropológico, para evitar la confusión con los de patrimonio etnológico y etnográfico, y así evitar la equiparación, que algunos hacen, de patrimonio antropológico con patrimonio cultural.

5..$^{\circ}$ Conservar elementos significativos que identifican a las sociedades vivas para que los cambios sociales no resulten más dramáticos de lo que son y documentar, de la mejor manera posible, los sistemas culturales para su conocimiento y posible reestudio en el futuro.

$6^{\circ}{ }^{\circ}$ Distinguir el término cultura del de patrimonio cultural, la primera es viva y cambiante, y en general no necesita de intervención, mientras que el patrimonio lo constituyen sólo aquellos aspectos considerados valiosos y dignos de ser conservados.

7..) La utilización con fines de rentabilidad social y económica del patrimonio, siempre que no se ponga en peligro su conservación, me parece aceptable y encomiable.

8. ${ }^{\circ}$ El patrimonio cultural no puede perder el carácter de totalidad e interrelación, pues éste no es la mera suma de los patrimonios regionales o parciales; por tanto parece necesaria la actuación conjunta de expertos de las distintas disciplinas para valorarlo, documentarlo, protegerlo y difundirlo.

\section{MECANISMOS SOCIALES DE PROTECCIÓN}

La ley del Patrimonio Histórico de Andalucía establece la obligación por parte de la sociedad de proteger el patrimonio: "Los propietarios, titulares de derechos o simples poseedores de bienes integrantes del PHA, se hallen o no catalogados, tienen el deber de conservarlos, mantenerlos y custodiarlos de manera que se garantice la salvaguardia de sus valores" (Art. 15.1). ¿Qué conserva la gente por propia iniciativa? El comportamiento en relación con el patrimonio está en estrecha relación con las clases y grupos sociales. El valor de lo nuevo es característico de las clases populares frente al valor de lo antiguo en las clases burguesas y las nuevas asimiladas; éstas a través del patrimonio - bienes, objetos y también sucesos y narraciones- establecen nexos entre unas generaciones y otras. La transmisión de escudos, genealogías e historias familiares entre nobles y burgueses es buena prueba de ello. El campesino ha valorado como patrimonio la tierra, la casa y en cierta medida los apellidos; las tradiciones culturales, por incuestionables, eran algo dado que no necesitaba 
protección, aunque, como bien sabemos, sometidas también a cambios, aunque no se tuviera percepción de ello. La herencia viene siempre cargada de situaciones emocionales para los herederos.

Mención especial merece el coleccionista, verdadero conservador profesionalizado, único defensor de determinadas formas de patrimonio antes de que las leyes lo protegiesen. Es cierto que en los coleccionistas los impulsos emocionales son más poderosos y priman sobre una adecuada metodología en la búsqueda y recolección, pero también es cierto que determinados museos, que con el tiempo terminarán por ordenarse de acuerdo con las orientaciones metodológicas de la museología, han sido posibles porque ha habido detrás un coleccionista. Citemos por su ejemplaridad a Francisco González Santana, colecionista de objetos durante toda su vida, que ha dado origen y nombre en Olivenza (Badajoz) al mejor museo de antropología de Extremadura.

Las asociaciones y grupos defensores del patrimonio se han convertido en una pieza clave en la protección del mismo. Somos conscientes de la dificultad de armonizar los intereses particulares con la protección del patrimonio, de aceptar que la propiedad privada tiene unos límites cada vez más estrechos impuestos por el beneficio común. Recordemos que históricamente legislar no ha significado siempre cumplir las leyes; por otra parte los organismos públicos no siempre entienden en cada caso hasta dónde llega su obligación de proteger, y en la confrontación no siempre hay intereses económicos, como la malicia trata de difundir, sino aquello de "yo con lo mío hago lo que quiero". Los medios de comunicación están jugando un papel decisivo en la toma de conciencia acerca del valor del patrimonio, no sólo publicando las aciones de las organizaciones proteccionistas sino también editando series sobre artesanías, fiestas, arqueología, oficios, gastronomía, etc. En este mismo sentido las administraciones públicas editan series, cuadernos, monografías que contribuyen a profundizar en esta línea. Estas actuaciones no quedarían completas si olvidáramos la necesaria actuación en los centros de enseñanza. La administración educativa está dando pasos para dotar a los docentes de materiales didácticos con los que facilitarles la tarea de difundir el respeto al patrimonio. En este sentido, en nuestra comunidad autónoma se ha incluido una asignatura optativa en el curso $3 .^{\circ}$ de la Enseñanza Secundaria Obligatoria, titulada "Patrimonio Cultural de Andalucía", así como se han puesto en marcha toda una serie de programas y proyectos didácticos en el área de cultura andaluza, tal como el Proyecto Demófilo, dedicado a la investigación-acción en la cultura tradicional andaluza, el Programa Maimónides, a la investigación científica y tecnológica, y los de Patrimonio Histórico, Flamenco, entre otros. 
¿Qué hacer cuando la protección o el mantenimiento de determinados rituales o prácticas tradicionales entran en conflicto con los valores actualmente vigentes? En estas situaciones el enfrentamiento entre abolicionistas y conservacionistas es radical y con frecuencia se aducen datos y argumentos que no responden a la verdad histórica. Los ejemplos más conocidos son las fiestas populares de toros, en las que las leyes y la demanda de los pueblos entran en conflicto; las fiestas de moros y cristianos en las que estructuralmente siempre ganan los cristianos que matan u obligan a convertirse a los moros, presentan también problemas a algunos grupos sociales. ¿Qué hacer ante el sentimiento de agravio de los descendientes o partidarios de los vencidos?, ¿eliminar la fiesta que forma parte del patrimonio de cientos de pueblos y andaluces?, ¿sería posible esto en ciertas comunidades en donde estas celebraciones son sus fiestas mayores? ¿es acertado intervenir modificando el sentido de las mismas, por ejemplo dando la victoria cada año a un bando? Es un debate abierto en el que no tienen cabida las prohibiciones, por ineficaces, ni tampoco el mantenimiento a ultranza aunque se trate de un fósil cultural. Sólo cabe la actuación democrática y de respeto a las comunidades que poseen este patrimonio, ello no empece el derecho que tienen los partidarios de la abolición a seguir defendiendo sus tesis. Como medida de protección se hace necesaria, incluso para fundamentar el debate, la documentación y registro del ritual o la ceremonia.

\section{LOS MECANISMOS LEGALES DE PROTECIÓN}

El primer paso legislativo para la protección del patrimonio cultural en España lo constituyó la Ley del Patrimonio aprobada por la República en 1933, aunque ya existía la figura de protección de declaración de "Monumento nacional. Durante el Régimen de Franco la ley no quedó abolida, pero su aplicación fue escasa. Necesidades más perentorias, junto a una concepción desarrollista, provocaron la destrucción de parte importante de nuestro patrimonio monumental y artístico. Será en la década de los setenta cuando empiece a tomar cuerpo entre algunos sectores de la sociedad y entre los representantes políticos la necesidad de controlar el proceso de ruina y desaparición del patrimonio, conservándolo y protegiéndolo, lo que culminará con la aprobación de la Ley de Patrimonio Histórico Español en 1985. Aparecen en este texto legal nuevas formas de patrimonio como el arqueológico, etnográfico, documental, bibliográfico, y el llamado inmaterial. Luego vendrán las versiones autonómicas, que matizan o innovan la ley general del Estado; concretamente 
la Ley del Patrimonio Histórico de Andalucía, aprobada en 1991, que incorpora figuras jurídicas muy novedosas en relación con el llamado patrimonio inmaterial y etnográfico.

La Constitución Española de 1978 en su artículo 46 recoge que "Los poderes públicos garantizarán la conservación y promoverán el enriquecimiento del patrimonio histórico, cultural y artístico de los pueblos de España y de los bienes que lo integren, cualquiera que sea su régimen jurídico y titularidad. La ley penal sancionará los atentados contra este patrimonio". Posteriormente en la Ley del Patrimonio Histórico Español (1985) ya aparece el concepto de patrimonio etnográfico, aunque no incluye ninguna figura específica de protección.

La Ley del Patrimonio Histórico Andaluz (1991) fue más sensible al patrimonio antropológico, pues acoge nuevas figuras jurídicas tales como los Lugares de interés etnológico, los edificios y estructuras de relevante interés etnológico. Define esta ley que "Forman parte del Patrimonio Etnográfico Andaluz los lugares, bienes y actividades que alberguen o constituyan formas relevantes de expresión de la cultura y modos de vida propios del pueblo andaluz" (Art. 61). Pero la principal novedad la constituye la figura de los llamados Lugares de interés etnológico: "Parajes naturales, conjuntos arquitectónicos, espacios públicos antiguos o actuales, construcciones o instalaciones vinculadas a formas de vida, cultura y actividades tradicionales del pueblo andaluz, que merezcan ser preservadas por su valor etnológicon (Art. 27-6). También tienen contenidos de interés antropológico, el Planeamiento urbanístico en que se tendrán en cuenta los valores que se pretenden preservar (Art. 64), el Patrimonio inmueble, en el que se contemplan los edificios y construcciones, viviendas populares con todos sus elementos y espacios rituales y de sociabilidad, y el Patrimonio mueble de interés etnológico, formado por bienes materiales y documentos (Art. 62). El Patrimonio inmaterial, recogido por primera vez en la ley de 1985, comprende: prácticas, saberes, rituales, expresiones verbales, artísticas y otras manifestaciones culturales.

Para su protección y fomento, la ley establece que tendrán preferencia sobre las demás actividades de su misma naturaleza para conocimiento, difusión, protección y subvenciones; también contempla conocimientos y actividades en peligro de desaparición: ayuda a su estudio, recogida en soportes seguros y difusión (Art. 63). Asimismo, la norma establece la inspección por la Administración de dichos bienes caso de estar catalogados, ordenar obras de mantenimiento en caso de peligro y la expropiación total o parcial por interés social. También establece compromisos para la propia Administración autonómica: el $1 \%$ de toda obra pública de la Junta de Andalucía debe ir destinado a trabajos de conservación y acre- 
centamiento del PHA (Art. 87), el 20\% de excavaciones arqueológicas se destinará a la conservación y restauración de yacimientos y materiales (Art. 89), las ayudas a la rehabilitación de viviendas (estudio y beneficios) se podrán aplicar a conservar y restituir inmuebles del PHA (Art. 92), se contempla para este fin el pago de deudas a la Junta y la aceptación de donaciones (Art. 87), y la cesión, uso y explotación de inmuebles, etc. (Art. 93). Las subvenciones se podrán aplicar, previa declaración por los técnicos, a obras de conservación y mantenimiento o custodia de excavaciones arqueológicas y actividades relacionadas con el patrimonio etnográfico (Art. 95), a propietarios mediante convenios, contratos y créditos refaccionarios condonables, ya sea vigente significativo o significativo en peligro, identificatorio del pueblo andaluz, de una actividad o profesión, de un grupo de edad o estrato y de una comunidad (Art. 96).

Las sanciones se éstablecen en razón del daño infligido, llegando hasta su expropiación, orientadas a la reparación y restitución del estado original. Se prevé la catalogación de bienes inmateriales y otros con carácter revisable, los informes preceptivos de los técnicos en antropología en planes urbanísticos, económicos y espacios naturales, fomentar medidas fiscales y otras en actividades y conocimientos relacionados con formas tradicionales de producción, la reglamentación de permisos y actuación en Bien de interés Etnológico, la documentación y estudio, especialmente en bienes inmateriales, la conservación de bienes muebles e inmuebles, la ayuda a su mantenimiento, evitando su mixtificación y dirigismo y la inclusión de estos bienes patrimoniales en el Catálogo general del PHA (Ar. 8.1).

Como órganos e instituciones se establecen los de carácter ejecutivo: Consejería de Cultura y sus delegaciones provinciales y los ayuntamientos. Especial relevancia mantienen las Comisiones provinciales del patrimonio histórico para la autorización de actuaciones y propuestas de catalogación y declaración de interés cultural (Art. 106). En cuanto a los consultivos, se crea el Consejo Andaluz del Patrimonio Histórico, en el que participan varias consejerías y las Comisiones andaluzas de bienes culturales: Bienes inmuebles, Muebles, Arqueología, Archivos, Museos, y de Etnología, que tienen entre sus funciones emitir informes, constituir jurados y asesorar en cuantos temas de carácter patrimonial se les sometan.

El papel de los ayuntamientos es muy delicado pero decisivo en la concienciación de los valores patrimoniales. Situados entre el marco legal, los técnicos y la realidad sociológica, frecuentemente abocados a tomar decisiones no siempre comprendidas y valoradas por la ciudadanía, presionados por las relaciones personales en el caso de núcleos rurales, ineficaces en las grandes urbes; con competencias muy amplias en los planes de ordenación urbana y normas subsidiarias y, sin embargo, con muy 
escasos recursos; todo ello conduce a que esta institución desempeñe un papel decisivo en la protección del patrimonio.

Se analiza el concepto histórico de patrimonio en el ámbito material y espiritual de los grupos sociales. Se define el término de patrimonio cultural y antropológico, estudiando sus postulados básicos y concepciones. Igualmente, las diferencias existentes entre antropología y patrimonio antropológico, así como los mecanismos sociales y legales para su protección, ejemplificados en el ámbito andaluz.

The author analyzes the historical concept of "Heritage" involved in the material and spiritual identity of social groups. He defines the term "Cultural and Anthropological Heritage" by examining its guiding principles and conceptions. He also discusses the differences between anthropology and anthropological heritage, as well as the legal and social mechanisms needed to protect such heritage as exemplified in Andalusia. 